(OPEN ACCESS

\title{
Exploring the characteristics, acuity and management of adult ED patients at night-time
}

\author{
Rebecca Simpson, ${ }^{\ominus}$ Susan Croft, Colin O'Keeffe, Richard Jacques, Tony Stone, \\ Nisar Ahmed, Suzanne M Mason
}

Additional material is published online only. To view, please visit the journal online (http://dx.doi.org/10.1136/ emermed-2018-208248).

School of Health and Related Research, University of Sheffield, Sheffield, UK

Correspondence to Dr Rebecca Simpson, School of Health and Related Research, University of Sheffield, Sheffield S1 4DA, UK:

r.simpson@sheffield.ac.uk

Received 2 November 2018 Revised 14 June 2019 Accepted 12 July 2019 Published Online First 30 July 2019

\section{Check for updates}

(C) Author(s) (or their employer(s)) 2019. Re-use permitted under CC BY-NC. No commercial re-use. See rights and permissions. Published by BMJ.

To cite: Simpson $R_{\text {, }}$

Croft S, O'Keeffe $\mathrm{C}$,

et al. Emerg Med J

2019:36:554-557

\section{ABSTRACT}

Objectives ED care is required for acutely unwell and injured patients 24 hours a day, 7 days a week. The aim of this study was to compare characteristics and activity of type $1 \mathrm{ED}$ attendances according to whether their time of arrival was during the day (08:00-18:00) or at night (18:00-08:00).

Methods Hospital Episode Statistics (HES) data from NHS Digital for all A\&E and admitted patient care activity provided by all acute (not mental health or primary care) NHS hospital trusts in Yorkshire and Humber (1 April 2011 to 31 March 2014) for adult patients were analysed. Adjusted linear and logistic regression was used to model the data.

Results Adjusted regression analysis results show that patients who attended ED at night waited an extra 18.76 (95\% Cl 18.62 to 18.89 ) $\mathrm{min}$ to be seen by a clinician. They also spent an additional $13.64(95 \% \mathrm{Cl} 13.47$ to 13.81) min total in ED. Patients who attended at night were OR 2.20 (95\% CI 2.17 to 2.23) times more likely to leave without being seen. They were also OR 1.26 $(95 \% \mathrm{Cl} 1.25$ to 1.27$)$ times more likely to re-attend the ED and were OR $1.20(95 \% \mathrm{Cl} 1.19$ to 1.21$)$ times more likely to present with non-urgent conditions. Overnight patients were more likely to be admitted to hospital, OR 1.09 (95\% Cl 1.09 to 1.10) times, however, those admitted were more likely to have a short-stay admission.

Conclusion There is an 'overnight effect' of patients attending EDs. Patients wait longer, leave without being seen, attend with non-urgent problems and are more likely to be admitted for a short stay. Further work is required to identify the potential underlying causes of these differences.

\section{BACKGROUND}

ED care is required for acutely unwell and injured patients 24 hours a day, 7 days a week. Ensuring that patients receive consistent high-quality, safe care regardless of the day of the week and time of presentation is important. NHS England has committed to provide a 'truly 7-day NHS' by extending access to general practitioners (GPs), improving access to healthcare advice and promising to deliver consultant assessment and review, diagnostic tests and consultant-led interventions every day of the week by $2020 .^{1}$

Harrison et $a l^{2}$ identify setbacks in the ED and delays in accessing acute care, caused by the lack of availability of specialist services outside normal working hours. ${ }^{2}$ A number of studies have identified differences in mortality for patients admitted

\section{Key messages}

What is already known on this subject?

- ED care is required for acutely unwell and injured patients 24 hours a day, 7 days a week.

- Previous research has shown that there are changes in patient care at the weekend and this has been controversially termed the 'weekend effect'; however, there has been less of a focus on an 'overnight effect'.

What this study adds?

- There is an 'overnight effect' of patients attending EDs.

- Patients wait longer, leave without being seen, attend with lower acuity problems and are more likely to be admitted for a short stay.

at the weekend compared with during the week, controversially termed the 'weekend effect'. 34

However, there has been less focus on the 'overnight effect'; exploring the differences between patients that present to hospital in the evening and night, compared with day. Although the weekend effect has been attributed to sicker patients attending at the weekend, ${ }^{5}$ we wanted to explore differences between night and day for those who present at the ED and their disposition (excluding mortality).

The aim of this study was to use Hospital Episode Statistics (HES) data from Yorkshire and Humber $(\mathrm{Y} \& \mathrm{H})$ to identify characteristics and outcomes of type $1 \mathrm{ED}$ attendances and admissions according to whether their time of arrival was at day (08:0018:00) or night (18:00-08:00).

\section{METHODS}

The study used pseudonymised HES data from NHS Digital for all A\&E and admitted patient care activity provided by all acute (not mental health or primary care) NHS hospital trusts in the $\mathrm{Y} \& \mathrm{H}$ region, from 1 April 2011 to 31 March 2014. Y\&H contains a mixture of large urban, small urban, suburban and rural settings, with a population of 5.4 million and 18 type 1 EDs (ie, consultant-led, 24 hours multispecialty service with full resuscitation facilities) including 4 major trauma centres. Therefore, we consider the setting to be generalisable to the UK population. Data for first attendances and unplanned re-attendances for adults aged 16 years and over were used. 


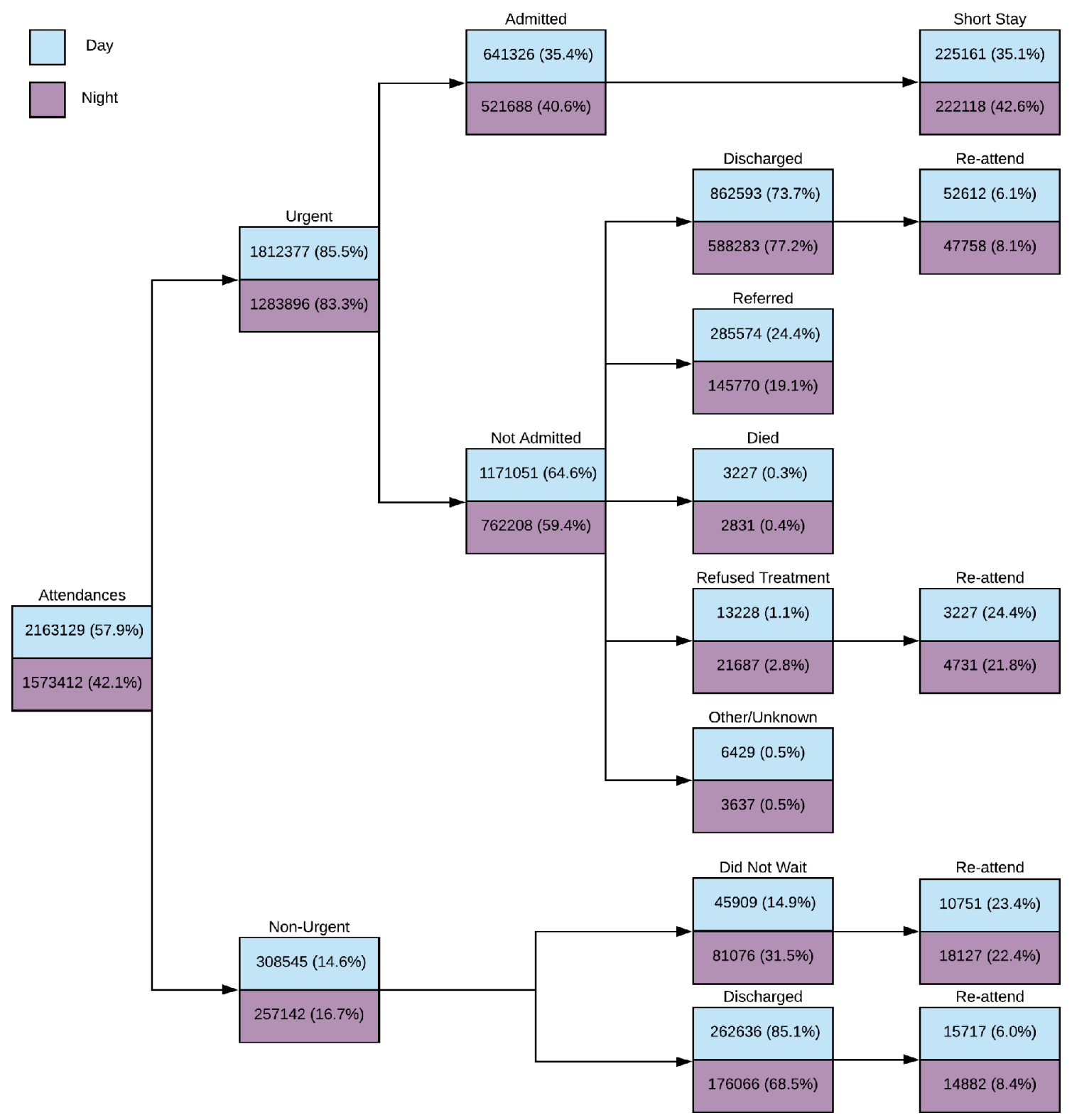

Figure 1 Patient flow split by night and day.

Comparative analyses were conducted for both day and nighttime. Chi-squared tests were used to compare proportions, t-tests were used to compare means and Mood's median tests were used to compare medians when the data were skewed.

Linear regression, adjusted for age, sex, Index of Multiple Deprivation score and arrival mode (including an interaction for age and arrival mode), was used to model how time of day affects continuous outcomes such as length of waiting and total departure time. Similar adjusted logistic regression models were used to model how time of day affects binary outcomes such as non-urgent attendances, admissions, those who did not wait, who re-attended, whether total time in ED was within the 4 hours target and short-stay admissions (less than two nights). Non-urgent attendances were identified using a previously described definition by O'Keeffe $e t a l^{6}$ : 'A first or unplanned return ED attendance with some recorded treatments or investigations all of which may have reasonably been provided in a non-emergency care setting, followed by discharge home or to GP care'. A table of the outcomes and their definitions is provided as online supplementary material. Non-urgent is defined as an outcome opposed to an attendance characteristic as patients will arrive to the ED believing they are urgent, it is only after the investigations, treatment and disposal that a patient is classed as urgent or non-urgent. Mixed effects models accounting for clustering within hospitals was tested; however, the models did not converge and the output produced was similar to the fixed effects model. Therefore, only fixed effects models were used in the analysis.

\section{RESULTS}

There were 3736541 ED attendances during the period studied, of which 1573412 (42.11\%) were at night. The patient pathway for those presenting at night and day is presented in figure 1 . Patients who arrived at night were younger than patients who arrived in the day (median: 41 years night vs 46 years day, $\mathrm{p}<0.001)$ and were more likely to arrive by ambulance $(42.30 \%$ night vs $29.74 \%$ day, $\mathrm{p}<0.001$ ) (table 1 ). They were also more likely to come from a more deprived area. 


\section{Short report}

Table 1 Attendance characteristics by time of presentation

\begin{tabular}{|c|c|c|c|c|}
\hline & Day & Night & Total & $P$ value \\
\hline Attendances & $2163129(57.89 \%)$ & $1573412(42.11 \%)$ & 3736541 & \\
\hline Attendance type & & & & $<0.001$ \\
\hline First attendance & 2011569 (92.99\%) & $1448111(92.04 \%)$ & 3459680 & \\
\hline Unplanned re-attendance & $151560(7.01 \%)$ & $125301(7.96 \%)$ & 276861 & \\
\hline Age (years) & & & & $<0.001$ \\
\hline Mean (SD) & $49.0(22.2)$ & $45.6(22.2)$ & $47.6(22.3)$ & \\
\hline Median (IQR) & $46(29-67)$ & $41(26-62)$ & $44(28-65)$ & \\
\hline Age (years) & & & & $<0.001$ \\
\hline$<45$ & $1025314(47.40 \%)$ & 858956 (54.59\%) & 1884270 & \\
\hline $45-74$ & $749100(34.63 \%)$ & 477399 (30.34\%) & 1226499 & \\
\hline$\geq 75$ & 388715 (17.97\%) & 237057 (15.07\%) & 625772 & \\
\hline Gender & & & & $<0.001$ \\
\hline Female & $1101724(50.93 \%)$ & 768991 (48.87\%) & 1870715 & \\
\hline Male & $1061166(49.06 \%)$ & 804230 (51.11\%) & 1865396 & \\
\hline Not known & $239(0.01 \%)$ & $191(0.01 \%)$ & 430 & \\
\hline Arrival mode & & & & $<0.001$ \\
\hline Ambulance & $643409(29.74 \%)$ & $665512(42.30 \%)$ & 1308921 & \\
\hline Other & $1519631(70.25 \%)$ & 907835 (57.70\%) & 2427466 & \\
\hline Not known & $89(<0.01 \%)$ & $65(<0.01 \%)$ & 154 & \\
\hline Index of Multiple Deprivation quintile & & & & $<0.001$ \\
\hline Q1 (most deprived) & $761973(35.23 \%)$ & $611246(38.85 \%)$ & 1373219 & \\
\hline Q2 & 452991 (20.94\%) & $331400(21.06 \%)$ & 784391 & \\
\hline Q3 & $372156(17.20 \%)$ & $252675(16.06 \%)$ & 624831 & \\
\hline Q4 & $346281(16.01 \%)$ & $225389(14.32 \%)$ & 571670 & \\
\hline Q5 (least deprived) & $215026(9.94 \%)$ & $137959(8.77 \%)$ & 352985 & \\
\hline Not known & $14702(0.68 \%)$ & $14743(0.94 \%)$ & 29445 & \\
\hline
\end{tabular}

Patients who attended at night waited longer to be assessed by a clinician. After the model was adjusted, patients waited an average of 18.76 minutes extra to be seen by a clinician if they arrived at night (table 2). Those who arrived at night also spent longer total time in ED. After model adjustment, patients spent on average an additional 13.64 minutes in ED if they arrived at night compared with day (table 2). They were also more likely to spend $>4$ hours in ED at night, thus breaching the emergency care standard (table 2).

Table 2 Activity outcomes by time of presentation-analysis (night vs day)

\begin{tabular}{|c|c|c|c|c|c|c|}
\hline & & & $\begin{array}{l}\text { OR } \\
\text { night (unadjusted) }\end{array}$ & $\begin{array}{l}\text { OR } \\
\text { night (adjusted) }\end{array}$ & $\begin{array}{l}\text { Additional time } \\
\text { night (unadjusted) }\end{array}$ & $\begin{array}{l}\text { Additional time } \\
\text { night (adjusted) }\end{array}$ \\
\hline & Day (\%) & Night (\%) & $\begin{array}{l}\text { Estimate } \\
(95 \% \mathrm{Cl})\end{array}$ & $\begin{array}{l}\text { Estimate } \\
(95 \% \mathrm{Cl})\end{array}$ & $\begin{array}{l}\text { Estimate } \\
(95 \% \mathrm{Cl})\end{array}$ & $\begin{array}{l}\text { Estimate } \\
(95 \% \mathrm{CI})\end{array}$ \\
\hline Non-urgent* & $308545(14.26 \%)$ & $257142(16.34 \%)$ & 1.18 (1.17 to 1.18$)$ & $1.20(1.19$ to 1.21$)$ & - & - \\
\hline Admitted* & $641326(29.65 \%)$ & $521688(33.16 \%)$ & $1.18(1.17$ to 1.18$)$ & 1.09 (1.09 to 1.10$)$ & - & - \\
\hline Did not wait* & $45909(2.12 \%)$ & $81076(5.15 \%)$ & 2.51 (2.48 to 2.54 ) & 2.20 (2.17 to 2.23$)$ & - & - \\
\hline Re-attend* & $140491(6.49 \%)$ & $136349(8.67 \%)$ & 1.37 (1.36 to 1.38$)$ & 1.26 (1.25 to 1.27$)$ & - & - \\
\hline Four-hour target ${ }^{*}$ & 2038900 (94.26\%) & $1439320(91.48 \%)$ & $0.66(0.65$ to 0.66$)$ & $0.71(0.70$ to 0.71$)$ & - & - \\
\hline $\begin{array}{l}\text { Short stay } \\
(<2 \text { nights })^{*} \ddagger\end{array}$ & $225161(10.4 \%)$ & $222118(14.1 \%)$ & 1.38 (1.36 to 1.39$)$ & 1.33 (1.32 to 1.35$)$ & - & - \\
\hline $\begin{array}{l}\text { Waiting timet } \\
(\mathrm{min})\end{array}$ & $\begin{array}{l}\text { Mean: } 64.8 \\
\text { SD: } 56.2 \\
\text { Median: } 52 \\
\text { IQR: } 25-92\end{array}$ & $\begin{array}{l}\text { Mean: } 83.7 \\
\text { SD: } 68.6 \\
\text { Median: } 70 \\
\text { IQR: } 32-122\end{array}$ & - & - & 18.83 (18.70 to 18.97$)$ & 18.76 (18.62 to 18.89$)$ \\
\hline $\begin{array}{l}\text { Total department timet } \\
(\mathrm{min})\end{array}$ & $\begin{array}{l}\text { Mean: } 144.3 \\
\text { SD: } 82.5 \\
\text { Median: } 136 \\
\text { IQR: } 82-201\end{array}$ & $\begin{array}{l}\text { Mean: } 162.1 \\
\text { SD: } 89.8 \\
\text { Median: } 160 \\
\text { IQR: } 98-218\end{array}$ & - & - & 17.76 (17.59 to 18.94$)$ & 13.64 (13.47 to 13.81$)$ \\
\hline
\end{tabular}

Day is the reference category.

*Logistic regression model with output as OR adjusted for age, sex, IMD and arrival mode.

tLinear regression model with output as mean difference adjusted for age, sex, IMD and arrival mode.

¥For admitted patients.

IMD, Index of Multiple Deprivation. 
Patients who attended at night were 2.20 times as likely to leave without being seen by a clinician. They were also more likely to re-attend the ED if they arrived during the night (table 2).

Night-time attendees were more likely to present with non-urgent problems that were amenable to management in alternative non-emergency settings.

Hospital admission rates were found to be higher at night than in the day; however, these night admissions were significantly more likely to be short-stay admissions (table 2). For night admissions, the mean length of stay was shorter than for those who were admitted during the day (5.25 vs 6.36 days) and similarly for median length of stay (12.42 vs 11.39).

\section{DISCUSSION}

Our results describe an 'overnight effect' for patients attending the ED. We found significantly higher rates of patients leaving without being seen and higher re-attendance rates. Patients also waited longer to be seen by a clinician, spent longer in ED and were more likely to breach the 4-hour target during the night compared with day. Previous studies have also found patients attending out of hours spent longer in ED and were more likely to breach the 4-hour target. ${ }^{78}$

Attendance patterns in our study were different at night-time with a higher proportion of non-urgent patients. Some of these patients attend in the early evening possibly due to reasons of convenience and the lack of availability of alternative health services at these times. Lack of access to primary care (both lack of capacity and ease of access on demand),,${ }^{910}$ and limited alternatives available ${ }^{11}$ has been shown to influence use of the ED for non-urgent care.

Although the patients attending at night are more likely to be non-urgent, they are also more likely to be admitted. This could be related to differences in case-mix within the urgent subgroup but could also be due to limited access to investigations and equipment or due to fewer senior clinical staff being available at night-time. Further research is required to understand these differences. Redesigning urgent care to provide more options for patients at times that are convenient to them, and resourcing EDs in order that they can deliver care that has parity with daytime hours would improve the differences identified in outcomes. However, identifying the causes for higher admission rates would require further investigation.

\section{Limitations}

Although analysing big data offers benefits in identifying trends across large populations, there are also limitations. The dataset does not allow for in-depth analysis of observed trends: in order to further understand variability, additional qualitative analysis is required. As data were analysed retrospectively, it means that trends observed may not be representative of current local practices.

There is a lack of consensus on the out-of-hours times across studies. The time, 18:00-08:00 hours, was chosen to coincide with the closing time of GPs. This could be a limitation as it could be difficult to compare with other studies which have defined different out-of-hours times.

A further limitation of the study is the limited case-mix adjustment, it was not possible to adjust for patient diagnosis due to the poor quality data in this field.

\section{CONCLUSION}

We found significant differences in the patterns of attendance and outcomes of patients accessing the ED during day and night. Further work is required to identify the potential underlying causes of these differences.

Contributors SMM, CO'K and RJ conceived the study. NA performed the background searches. Data linkage was performed by TS and statistical analysis of results by RS and RJ. Interpretation of data was performed by RS, SMM, SC, CO'K and RJ. RS and SC drafted the initial manuscript and all authors contributed to its revision.

Funding The research was funded by the NIHR CLAHRC Yorkshire and Humber, www.clahrc-yh.nihr.ac.uk

Disclaimer The views expressed are those of the author(s), and not necessarily those of the NHS, the NIHR or the Department of Health.

Competing interests The authors report grants from NIHR, inside and outside the submitted work.

\section{Patient consent for publication Not required.}

Ethics approval Ethical approval was obtained from the National Health Service Health Research Authority: South West Exeter (14/SW/1014).

Provenance and peer review Not commissioned; externally peer reviewed.

Data sharing statement Data may be obtained from a third party and are not publicly available.

Author note The Out of Hours Effect. Exploring patterns of ED attendance and admission during weekdays, weekends and night-time. HSRUK Conference 2018. An overnight effect rather than a weekend effect? Exploring patterns of ED attendances during weekdays, weekends and night-time. EUSEM 2018.

Open access This is an open access article distributed in accordance with the Creative Commons Attribution Non Commercial (CC BY-NC 4.0) license, which permits others to distribute, remix, adapt, build upon this work non-commercially, and license their derivative works on different terms, provided the original work is properly cited, appropriate credit is given, any changes made indicated, and the use is non-commercial. See: http://creativecommons.org/licenses/by-nc/4.0/.

\section{REFERENCES}

1 NHS. NHS England - Seven day hospital services: our ambition. https://www.england. nhs.uk/seven-day-hospital-services/our-ambition/ (accessed 17 Jul 2018).

2 Harrison M, Ryan T, Gardiner C, et al. Patients' and carers' experiences of gaining access to acute stroke care: a qualitative study. Emerg Med J 2013;30:1033-7.

3 Lilford RJ, Chen YF. The ubiquitous weekend effect: moving past proving it exists to clarifying what causes it. BMJ Qual Saf 2015;24:480-2.

4 Bray BD, Steventon A. Data linkage studies can help to explain the weekend effect. Lancet 2017;390:8-9.

5 Sun J, Girling AJ, Aldridge C, et al. Sicker patients account for the weekend mortality effect among adult emergency admissions to a large hospital trust. BMJ Qual Saf 2019;28:223-30.

6 O'Keeffe C, Mason S, Jacques R, et al. Characterising non-urgent users of the emergency department (ED): a retrospective analysis of routine ED data. PLOS One 2018; 13:e0192855.

7 Bobrovitz N, Lasserson DS, Briggs ADM. Who breaches the four-hour emergency department wait time target? A retrospective analysis of 374,000 emergency department attendances between 2008 and 2013 at a type 1 emergency department in England. BMC Emerg Med 2017;17:32.

8 Anselmi L, Meacock R, Kristensen SR, et al. Arrival by ambulance explains variation in mortality by time of admission: retrospective study of admissions to hospital following emergency department attendance in England. BMJ Qual Saf 2017;26:613-21.

9 Cowling TE, Harris MJ, Watt HC, et al. Access to general practice and visits to accident and emergency departments in England: cross-sectional analysis of a national patient survey. Br J Gen Pract 2014;64:e434-9.

10 Hummel K, Mohler MJ, Clemens CJ, et al. Why parents use the emergency department during evening hours for nonemergent pediatric care. Clin Pediatr 2014;53:1055-61.

11 Wong WB, Edgar G, Liddy C, et al. Can after-hours family medicine clinics represent an alternative to emergency departments? Survey of ambulatory patients seeking afterhours care. Can Fam Physician 2009;55:1106-7. 